\title{
GROUPING OF MAJOR CHANGES IN CONCEPTUAL FRAMEWORK OF FINANCIAL REPORTING AND ANALYSIS OF NEW CHALLENGES
}

\author{
Liudmyla Shkulipa* \\ State Statistics Service of Ukraine, National Academy of Statistic, Accounting and Audit, Ukraine \\ E-mail: job.shkulipa@gmail.com
}

(Received: November 2020; Accepted: January 2021; Published: May 2021)

\begin{abstract}
This article aims to research the major changes in the Conceptual Framework of Financial Reporting; to find out the new gaps in the current document; to group the changes into categories; to analyze the current difficulties and consequences of these changes for a consistent understanding between standard-setters and practitioners. The Onion research model based on the quantitative data collection with elements of descriptive analysis was considered as important contributions to the research methodology of the Conceptual Framework for Financial Reporting investigation. As a result, a comparative analysis of the financial reporting concepts was made between July 1989, September 2010, and March 2018. The implications of results are two-fold. On the one hand, the revised Conceptual Framework is a more comprehensive set of concepts that enhance the understanding between practitioners and standard-setters. On the other hand, it consists of the new gaps most of them in the "Updating" category. It is concluded that this innovation complicates the reporting process for practitioners because it requires using of additional judgments. Besides, the investigation shows some IFRS are not justified within only the Conceptual Framework that might be the subject for further research.
\end{abstract}

Keywords: Conceptual Framework for Financial Reporting, concepts, major changes, IASB, IFRS, IAS, gaps

JEL Classification: M40, M41, M49

\section{Introduction}

IFRS is now sufficiently complete to cover almost all transactions and events within the scope of the particular standard, although it does not exclude the need to use the Conceptual Framework as the standards setters as participants, experts,

\footnotetext{
*Corresponding author: Liudmyla Shkulipa. E-mail: job.shkulipa@ gmail.com
}

Copyright $(\mathrm{C} 2021$ The Author(s). Published by VGWU Press

This is an Open Access article distributed under the terms of the Creative Commons BY 4.0 license (Creative Commons - Attribution 4.0 International - CC BY 4.0) which permits unrestricted use, distribution, and reproduction in any medium, provided the original author and source are credited. 
Shkulipa, L., (2021)

Grouping of major changes in conceptual framework of financial reporting and analysis of new challenges

auditors, lawyers, scholars, and students of economic faculties. The Conceptual Framework for Financial Reporting was developed to guide the International Accounting Standards Board - to assist the development of new and revising existing standards based on consistent concepts, resulting in financial information that is useful to investors, lenders and other creditors; the national regulatory authorities - to develop accounting standards; the preparers of financial reports - to apply IFRS on practice, for example, auditors - when forming an opinion on the compliance of financial statements with international standards, or to develop consistent accounting policies for a specific transaction or event where no Standard is applicable or Standard allow a choice of accounting policy; the users - to understand the financial statements and interpret Standards; all persons who are interested in IASB activities (Kesjan and Mullinova, 2017). This paper investigates the major changes in the Conceptual Framework of Financial Reporting and new gaps in the current version; it aims to group the changes into four categories, such as "Priority", "Filling gaps", "Updating" and "Clarifying"; and to analyze the current difficulties and consequences of these changes for a consistent understanding between setters and practitioners. There are three reasons to focus on this issue.

The first is that the Conceptual Framework for Financial Reporting is used by many countries in orienting the national accounting and financial reporting standards to global markets. This is especially the case when some rules are not prescribed by IFRS, and national rules contradict international ones.

Second, there is growing interest in the revised Conceptual Framework for financial reporting due to the consistent understanding by standard-setters and practitioners (Cordery and Sinclair, 2016); Tokar, 2018; Handley et al., 2020). The Conceptual Framework is the necessary foundation on which all IFRS accounting philosophy is built and is an integral part of standards. This document is not part of IFRS but is directly related to them. The Conceptual Framework is rarely the main point when analyzing financial statements, and yet it is at the heart of every accounting standard ensuring consistency of terminology, recognition, and measurement (Rodgers, 2007). Thus, everyone must learn this document before beginning to work with any IFRSs or IASs.

Third, there is a lack of consistent results of prior studies that have investigated the IFRS issues more frequently and rules, particular, in terms of the need for measurement concepts (Barth, 2014), market recognition and disclosure (Barth et al., 2003), asymmetric timeliness of earnings (Basu, 1997; Healy et al., 2001), income concepts (Bromwich et al., 2010), IASB comprehensive project (Van et al., 2007). The researches that related only to the Conceptual Framework were presented within some reflective comments (Swapan, 2012; Gordon et al., 2015; Smieliauskas, 2015; Smieliauskas et al., 2017) and conceptual gap analysis 
Shkulipa, L., (2021)

Grouping of major changes in conceptual framework of financial reporting and analysis of new challenges

(Beerbaum et al., 2016) for financial reporting (Sutton et al., 2015), the unit of account in financial reporting (Bunting, 2010), the accounting uncertainty and 'balance sheet' approach (Barker and Penman, 2013), the decision-usefulness and stewardship (Cordery et al., 2016), The difference Conceptual Frameworks for public and private enterprises were considered by Thornton (2015). Thus, these prior studies were conducted mostly in the time range before the 2018 changes in the Conceptual Framework of IASB. It remained the open topics about the case and consequences of the revised Conceptual Framework.

Even though among the current papers it was found the topics about the importance of the earning management concepts (Dhanda et al., 2018) and the Conceptual Framework in developing the new lease IFRS 16 (Kabir et al., 2018), these studies are not enough to describe all possible challenges in the current Conceptual Framework. The prior investigated challenges in the accounting of uncertainty (Barker et al., 2018), reporting financial instruments (Abdel-khalik, 2019), use of financial reporting after changes in 2018 (Davern et al., 2019) have a link to this study but also they are not disclosure all new existing difficulties in the revised Conceptual Framework of 2018.

In addition, as stated by Huber (2020), the Conceptual Framework (FASB) is illogical and based on autocratic declarations, faulty assumptions, fallacious conclusions, contradictory assertions, internal inconsistencies, erroneous identification of resources, ignorance of securities laws, and circularity of reasoning. His critique of the FASB Conceptual Framework as bad in legitimacy and integrity raised the following questions in this study.

Research Question 1. What are the major changes in the revised Conceptual Framework for Financial Reporting (IASB) in 2018?

Research Question 2. How can be these major changes grouped and classified?

Research Question 3. Are these major changes in the revised Conceptual Framework new difficulties between understanding of practitioners and standardsetters?

Research Question 4. What are the current gaps in the Conceptual Framework for Financial Reporting?

Therefore, the analysis of this document is necessary to understand the new changes in IFRS reporting concepts, which will help to properly orient both international and national economies to joint reporting. The study of the main changes in the Conceptual Framework introduced by the IASB in March 2018 will help to group them into four categories based on the quantitative collection internal secondary and primary data, interpretivism research philosophy, inductive research approach with elements of descriptive quantitative analysis, aggregation, and synthesis. As a result, a comparative analysis of the financial reporting concepts has been begun in July 1989 .

22 S sciendo Studia Universitatis "Vasile Goldis" Arad. Economics Series Vol 31 Issue 2/2021 ISSN: 1584-2339; (online) ISSN: 2285 - 3065

Web: publicatii.uvvg.ro/index.php/studiaeconomia. Pages $20-44$ 
Shkulipa, L., (2021)

Grouping of major changes in conceptual framework of financial reporting and analysis of new challenges

The results of this paper indicate the causes that led to the changes in the Conceptual Framework of Financial Reporting in 2018 grouping them into four categories, such as "Priority", "Filling gaps", "Updating" and "Clarifying". Also, the findings show the difficulties and consequences of these changes for a consistent understanding between setters and practitioners. Overall, the results suggest the positive effects of the new concepts within the "Clarifying" "Updating" categories on the quality of financial reporting. Moreover, the results make several contributions to the literature. First, while there were a considerable number of studies on the IFRS issues, their impact on the financial reporting quality and link with the Conceptual Framework, it was summarized the main Conceptual Framework' paragraphs and chapters by building the comparative table for the document version of 1989, 2010 and 2018. Second, although the Conceptual Framework is more comprehensive than in 2010, the document consists of new gaps. They are also considered and explained as the IASB's members tried also to show to practitioners their tendencies while revision the issued Conceptual Framework in March 2018. Third, the used in this study method are considered also as important contributions to the research methodology of the study that may be related with the Conceptual Framework comparison, view, analysis in the further consideration or investigation

This paper is organized as follows. The prior literature related to research questions is presented in Section 2. Section 3 describes the research methodology and samples. Section 4 provides and interprets the result of the main analysis of the major changes in the current Conceptual Framework. A concluding discussion is presented in Section 6.

\section{Prior Literature Review}

As mentioned above, the prior studies have investigated the IFRS issues more frequently than the Conceptual Framework's ones. The literature review allows us to divide the relevance of the topic into two periods - before and after the changes (2018). The prior studies before 2018 have shown that Conceptual Framework2010 is more improved than the Conceptual Framework-1989 (Swapan, 2012). Although, the authors note that the document of 2010 was issued in incomplete form as not planned by the setters.

Moreover, some scientists indicate reducing the differences between the existing and previous projects of frameworks. So, all attempts to make international accounting standards closer and to develop a unified Conceptual Framework have given positive results. As stated by Bullen (2005), the common Conceptual Framework of the IASB and the FASB (2010) was necessary to make the accounting standards "principles-based", because they could not be a set of conventions, but must be rooted in fundamental concepts. Consequently, the 
Shkulipa, L., (2021)

Grouping of major changes in conceptual framework of financial reporting and analysis of new challenges

fundamental concepts would be the Conceptual Framework for Financial Reporting on various issues to harmonize financial accounting and reporting (Bullen \& Crook, 2005).

Johnson (2004) mentioned the conceptual framework as the document provides the unity and consistency that is required to help in making those decisions. "Without a set of unified concepts, standard setters are like a ship in a storm without an anchor". According to Pounder (2010), Conceptual Frameworks' concepts tend to be "general in nature, broad in scope, and stable over time". Therefore, the authors argued, to eliminate the need to restore core concepts whenever it develops or updates, it needs "by consistently referring to a stable conceptual framework, a standards setter is more likely to promulgate standards that are consistent with each other as well as with significant assumptions and constraints" (Pounder, 2010). Also, Cordery and Sinclair (2016) identified a strong influence of European IASB members on changing the purpose of financial reporting in the Conceptual Framework-2010, noting that theory (setters) has one goal and practice (potential users) have other needs. This explains the Research Question №3.

Besides, given that the main purpose of the Conceptual Framework is to provide principles for the development of accounting standards, Sutton et al. (2015) considered their theoretical inconsistency with the standards, which should always be substantiated in practice. Among the frequent discrepancies, the authors call the assumption of fair value, assets, and liabilities, the preparation of additional income statements to focus on operating flows. Barker and Penman (2013) research the moving Conceptual Framework forward in terms of Accounting Uncertainty and the current 'balance sheet' approach. These studies explain the Research Question №1.

The important academic research is the study of Gordon et al. (2015), in which comments focus on four main areas required for the standard-setters when considering the revised Conceptual Framework: 1) recognition and derecognition, 2) measurement, 3) presentation and disclosure, and 4) other comprehensive income. The article supports the general goal of the IASB to develop one set of generally accepted accounting standards based on an integrated and comprehensive Conceptual Framework. Therefore, this explained the need to develop a new version of the document, separate from the FASB.

The comparison $1989^{\text {th }}$ and $2010^{\text {th }}$ Conceptual Frameworks was made by Swapan (2012), which explained not a comprehensive disclosure of all concepts of financial reporting in the joint project that was intended to be issued by IASB and FASB together.

The conducted researches after 2018 revealed, first, that the Conceptual Framework-2018 should provide timely access to reliable information on the financial position of companies to its users (Dhanda et al., 2018). In particular,

24 Sciendo Studia Universitatis "Vasile Goldis" Arad. Economics Series Vol 31 Issue 2/2021 ISSN: 1584-2339; (online) ISSN: 2285 - 3065

Web: publicatii.uvvg.ro/index.php/studiaeconomia. Pages $20-44$ 
Shkulipa, L., (2021)

Grouping of major changes in conceptual framework of financial reporting and analysis of new challenges

scientists noted that revenue management is the first step in fraud, so research concepts should focus on revenue management. Although as far as the updated Conceptual Framework is concerned, it has not been mentioned by scientists.

Second, the requirements of the new IFRS, in particular IFRS 16, are justified not only within the Conceptual Framework (Kabir et al., 2018). The authors explain this by mitigating the impact of the consequences - high implementation costs. Also, there are cases where the IASB has not used appropriate concepts to justify lease accounting requirements. This raises the incomplete coverage of financial reporting concepts in the updated document.

Third, the balance sheet approach is necessary but insufficient in the Conceptual Framework-2018 (Barker et al., 2018) in terms of the accrual method as a special source of information for investors when the investment results are uncertain. In this sense, Barker et al. (2018) believe that uncertainty undermines the balance sheet (because uncertain assets are unrecognized) and the income statement (because mismatching is unavoidable). As a result, they propose to provide information not only by the balance sheet approach, but also to divide the uncertainty into mismatching and matching in the income statement. This position of the authors once again emphasizes the need to study the Conceptual Framework in detail in terms of innovations to improve them by grouping (RQ №2).

As the reviewed studies showed some gaps and disadvantages in the Conceptual Framework 2018, in this article it was decided to group all changes in the Conceptual Framework into four categories (RQ №2): a) filling gaps that existed before 2018 - in the "Filling gaps" group, b) clarification of uncertainties in past concepts (1989) or return them without any changes, which is assumed to be the main advantage of the Conceptual Framework IASB 2018 - in the "Clarifying" group, c) changed priority concepts - in the "Priority" group, d) updates that did not exist in none of the Conceptual Framework versions previously - in the "Updating" group.

Fourth, the studied motives of the participants in the process of standard-setting (Handley et al., 2020) provide conclusions that this development process is managed by a certain elite close around the IASB. The exciting research made by Cade et al. (2019) in terms of questions about an asset and a liability was found despite the data used by 2016. As the 2015 Draft Document states, "do not need not be convinced or even likely that the resource will bring economic benefits. It is only necessary that the economic resource already exists and that there is at least one circumstance in which it can bring economic benefit" (IASB, 2015). That is, for the asset existence, there must be "potential to produce economic benefits" (IASB, 2015, p. 40), for the liability - "potential to require the entity to transfer an economic resource to another party" (IASB, 2015, p. 43). The main reasons that 
Shkulipa, L., (2021)

Grouping of major changes in conceptual framework of financial reporting and analysis of new challenges

led to changes in the asset and liability terms were the direct misinterpretations of probability or expected economic benefits (see Figure 1).

\section{Standard Setters' Concern}

- Misinterpretation of the words "probable" or "expected"

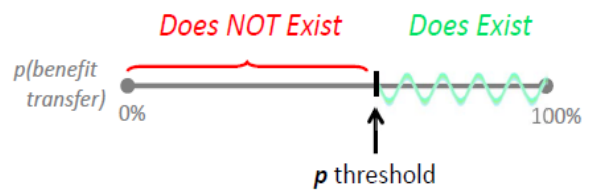

vs. Standard Setters' Intention

- Asset = "present right"

- Liability = "present obligation"

Does NOT

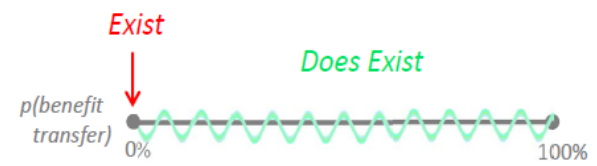

Figure 1 Reconciliation between intentions of new asset and liabilities definitions and the results of their correct understanding

Source: based on Cade et al., 2019

Therefore, to improve their understanding and search for new, more relevant, asset and liability definitions, in 2016 the IASB conducted a survey among accountants' seniors and beginners about (a) whether an asset exists for the payee, or b) whether there is an obligation for the payer in the ordinary transaction (Cade et al., 2019). Respondents needed to consider the situations in the context of different probability thresholds and with different asset and liability definitions. The obtained results are too useful and are shown in Table 1.

Table 1 Proportions of participants' positive responses about asset and liabilities existence

\begin{tabular}{|c|l|c|c|c|c|c|}
\hline \multirow{2}{*}{$№$} & \multicolumn{2}{|c|}{ Probability Threshold } & \multicolumn{2}{|c|}{ ASSET } & \multicolumn{3}{|c|}{ LIABILITY } \\
\cline { 3 - 7 } & & $20 \%$ & $80 \%$ & $1 \%$ & $20 \%$ & $80 \%$ \\
\hline 1 & No Definition & $37 \%$ & $87 \%$ & $62 \%$ & $60 \%$ & $65 \%$ \\
\hline \multirow{2}{*}{2} & $\begin{array}{l}\text { Old Definition (incl. a probable future } \\
\text { economic benefit) }\end{array}$ & $\begin{array}{c}38 \% \\
25 \% *\end{array}$ & $\begin{array}{c}95 \% \\
94 \% *\end{array}$ & - & $67 \%$ & $70 \%$ \\
\hline \multirow{2}{*}{3} & $\begin{array}{l}\text { Old Definition (incl. a potential future } \\
\text { economic benefit) }\end{array}$ & $\begin{array}{c}78 \% \\
60 \% *\end{array}$ & $\begin{array}{c}94 \% \\
92 \% *\end{array}$ & $\begin{array}{c}- \\
81 \% *\end{array}$ & $\begin{array}{c}75 \% \\
84 \% *\end{array}$ & $\begin{array}{c}85 \% \\
89 \% *\end{array}$ \\
\hline
\end{tabular}

Note. $*$ Responses of experienced experts in accounting.

Source: based on Cade et al., 2019

Consequently, the results of the survey showed that the old definitions did not affect the judgment of the assets and liabilities' existence. Thus, the new formulations have helped to understand the IASB intent better but have not 
Shkulipa, L., (2021)

Grouping of major changes in conceptual framework of financial reporting and analysis of new challenges

eliminated the problem of assets and liabilities definitions. In particular, it turns out that the proportion of respondents $(62 \%)$ with a $1 \%$ probability of a liability existence coincides with the proportion of respondents who set a high probability threshold for it - more than $65 \%$. As a result, it was found that participants use a higher probability threshold in recognizing assets than in recognizing liabilities, but the new changes in the assets and liabilities definition align participants' judgments more closely with standard-setters' intentions (see Figure 1).

Figure 1 helps to understand the reason for updating the symmetric prudence in the new Conceptual Framework and accepting the new asset and liability definitions because the symmetrical identification of an asset and liability can ensure consistency between participants and setters (see Figure 2).

\section{\begin{tabular}{|l|l|l|} 
Symmetric Identification & -OR- & Asymmetric Identification
\end{tabular}}
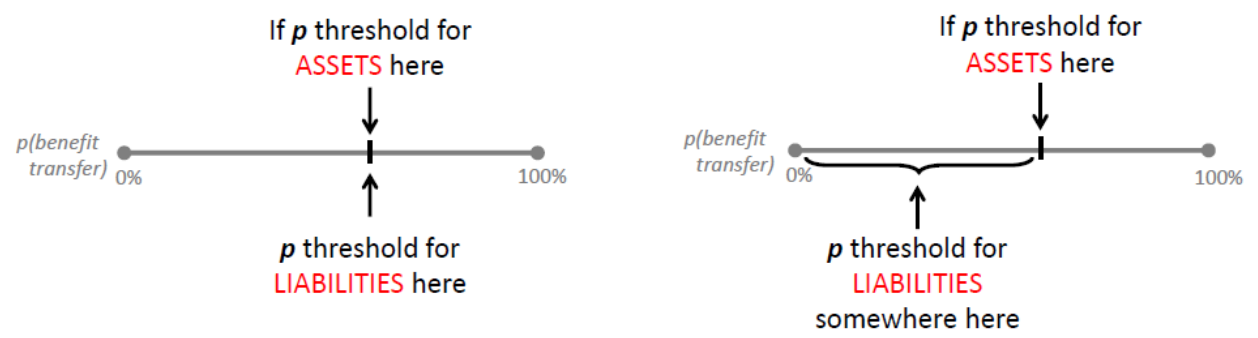

Figure 2 Reconciliation between intentions of new asset and liabilities definitions and the results of their correct understanding

Source: based on Cade et al., 2019

Figure 2 illustrates that after the changes in 2018, the economic resource has acquired a definition of the current right that has the potential to generate economic benefits, and a current obligation has become a necessity that the entity has no practice ability to avoid. Only a low probability of economic benefits might affect the decision to recognize and measurement of the asset (CF, p. 4.16, 2018), and a low probability of an economic benefits transferring might affect the decision to recognize and evaluate a liability $(\mathrm{CF}, \mathrm{p} .4 .38,2018)$. That is, the content remains unchanged in substance but a different formulation. As relevant Mary Tokar, International Accounting Standards Board member remarked: "Sometimes changing words in a standard encourages a re-examination of past practices" (Cade et al., 2019). It is well appropriate for changes in the Conceptual Framework.

Generally, investigations confirm that people are not experts in probabilistic judgments (Bernstein, 1998), and thus often simplify the task to make the 
Shkulipa, L., (2021)

Grouping of major changes in conceptual framework of financial reporting and analysis of new challenges

necessary decision (Kahneman and Frederick, 2002). In particular, if there is a $100 \%$ probability, then the benefit will come, and if the probability is lower than $100 \%$, then there is a threshold, which is subjective for everyone.

An example is a lawsuit, where if you win, the liability is zero; if you lose, the liability is 100 (contingent). If you have a 50\% chance of losing, then you have an expected value of 50 that can not be guaranteed as a real result. Therefore, it is not useful financial information that does not contribute to the achievement of the Conceptual Framework's objective. Another example is the indefinite tax items. Guidance on general accounting principles in the US for uncertain tax items requires recognition of the enormous amount (greater than $50 \%$ chance) of being paid.

This investigation founds reasons for definitions changes and illustrates the consequences of these changes to understand the Board's intentions better. Therefore, the question of whether the intentions of the setters correspond to the understanding of their projects in practice contributed to the Research Question №3.

Besides, the Research Question № 1 is explained by those studies in which scientists denied the quality of the FASB Conceptual Framework (Huber, 2020) and its focus on public interests, in others, on the contrary, proposed to put the GAAP Conceptual Framework as the dominant element governing standards and professional practice (Smieliauskas et al., 2017). Huber's opinion (Huber, 2020) indirectly revealed Davern et al. (2019) on the usefulness of non-GAAP financial statements. Their conclusions, in particular, criticize the legislative measures in the field of accounting and do not consider GAAP information more important than non-financial indicators used by investors both for the image and for the real assessment of the financial position of the entities.

Thus, the purpose of this study is to research the major changes in the Conceptual Framework of Financial Reporting-2018 (RQ3) by grouping them into the "Priority", "Filling gaps", "Updating" and "Clarifying" categories (RQ2), indicating the new gaps (RQ4) and analyzing the current difficulties of these changes in a consistent understanding by standard-setters and practitioners (RQ3).

\section{Research methodology}

According to the observed above prior studies, it was not found the used research methodology that is similar to this aim of the paper. Thus, the Research Onion model, as one of the most popular models in academic researches (Saunders et al., 2012), was chosen. Regarding this, the research methodology was prepared by following the particular structure to make the research process more comprehensible for the readers. 
Shkulipa, L., (2021)

Grouping of major changes in conceptual framework of financial reporting and analysis of new challenges

\subsection{Research Philosophy}

The research philosophy in this study was based on the interpretivism to group diverse approaches and interpret elements of the study. The reason for this choice was related to the main goal of this study - to analyze the new challenges among the major changes in the revised Conceptual Framework for Financial Reporting (2018) - because the major changes require to be interpreted at the first step of the study.

\subsection{Types of Research}

As the research area do not include any immediate practical implications and its findings cannot be used to solve specific business problems, the type of research according to the purpose and nature of the study was fundamental involving the quantitative and analytical characteristics based on the historical performance data to analyze the major changes in the Conceptual Framework after 2018 and make the critical evaluation of the subject. The used fundamental type of research aimed to contribute to the literature the theoretical analysis of the main Conceptual Framework' paragraphs and chapters by building the comparative table for the document version of 1989, 2010, and 2018. Also, it helped to expand the scientific understanding of the new changes in the Conceptual Framework of 2018.

\subsection{Research Approach}

According to the three research questions, the inductive approach was used in this study to achieve the aim and objectives during the research process. This explained the reason for theories or hypotheses absent in the paper. As the inductive reasoning should be based on learning from experience, the Conceptual Framework for Financial Reporting was considered using the author's experience in accounting practice and some comments of the IASB's members (Tokar, 2019). The constructed research questions (RQ1, RQ2, RQ3) have not been investigated currently in so comprehensive manner. It helped to observe the large information about three documents of the Conceptual Framework (1989, 2010, 2018), to analyze major changes of the Conceptual Framework using the explanations of existing problems before 2018 and predicting the possible ones after 2018. As a result, the generalizing from the specific concepts to the general groups, such as "Priority", "Filling gaps", "Updating" and "Clarifying", was made by the induction.

\subsection{Research Design}

Moreover, as the research aim was to explain the causes and consequences of these new changes in the Conceptual Framework, the research design was explanatory (conclusive) with elements of the contribution of the cause-and-effect-relationship. 
Shkulipa, L., (2021)

Grouping of major changes in conceptual framework of financial reporting and analysis of new challenges

It helped to provide a final and conclusive answer to the research questions (RQ1, RQ2, RQ3), built-in Section 1, explaining the causes of the new additions in the Conceptual Framework of 2018 and indicating their effect for further interpretations by practitioners. As the different books consist of different meanings on research design, the research design is also descriptive that matched with the target paper to describe the current topics, in particular, focused on the Conceptual Framework's paragraphs, chapters, categories, including the comparative table description.

\subsection{Time Horizon}

In this study, it was gathered data about the concepts of financial reporting at several points in time - 1989, 2010, and 2018. It means it was used the longitudinal time of the horizon. It helped to develop the comparative table tracking changes over time. As a result, it was obtained the analysis of normative concepts in three different periods.

\subsection{Data Collection Methods}

To collect data for this investigation it was used the internal secondary data because the Conceptual Framework's information of 1989 and 2010 had been previously published in journals (see Section 2), online portals, the IASB website, and other sources. However, the primary data of changes in the Conceptual Framework for Financial Reporting in 2018 was also required to be collected because in the observed literature and other web-portals published it was not existing but the purpose of this study was forced to collect it separately. Thus, in this study, to collect primary data, it was used the longitudinal type of sampling for the previous scientist's studies and normative data. It made this research more original, but it required more time and effort to present it shortly. For this, it was studied only the official document of the Conceptual Framework at the IASB's website (Conceptual Framework, 2018). That is why the secondary data was gathered and performed after analyzing 320 paragraphs and 8 chapters of the Conceptual Framework-2018.

As mentioned above research questions involve describing subjective experiences, interpreting meanings, and understanding concepts of financial reporting by IFRS, which was used the qualitative research. The use of a qualitative approach aimed to understand this investigation from the viewpoint of researchers in accounting and financial reporting. Despite the qualitative research has subjectivity, it helped to group the major changes of the Conceptual Framework into four categories that were highlighted based on the comparative table in Appendix A. The comparative table was described due to the relevance in the previous studies of the Conceptual 
Shkulipa, L., (2021)

Grouping of major changes in conceptual framework of financial reporting and analysis of new challenges

Framework, however, in terms of different concepts, including the Conceptual Framework of 1989, 2010.

\subsection{Data Analysis Methods}

As a result, the comparative analysis of the financial reporting concepts had been presented from July 1989 till now. This analysis was based on 320 paragraphs and 8 chapters of the Conceptual Framework of 2018; 125 paragraphs and 4 chapters of the Conceptual Framework of 2010; and 110 paragraphs and no chapters of the Conceptual Framework of 1989. The final sample was presented as a comparative table of major changes in the Conceptual Framework for Financial Reporting in the 2018 to 1989 and 2010 versions (see Appendix A). In this study, the self-developed comparative table was performed firstly and allowed to highlight the changes in the Conceptual Framework of 2018. It helped to group these changes in the four categories that were explained above.

Appendix A summarizes the sample selection process. To construct this sample, it was used as a bibliometric analysis and analysis of the normative Conceptual Frameworks of 1989, 2010, and 2018 years. As noted by Merigo et al. (2017) bibliometric is very useful for the organization of existing knowledge within the scientific discipline. The provided bibliometric analysis in this paper aims to do a systematic review of the scientific literature on IFRS and Conceptual Frameworks. It helped to review several articles that study the Conceptual Framework literature for different periods using the inductive research methods with elements of aggregation and synthesis. The normative analysis of documents was also useful to check the literature review with appropriate data of the Conceptual Frameworks.

\subsection{Structure of Research}

Overall, the performance strategy to reach the main goal of this paper could be described as follows.

In the first step, the paragraphs, chapters of the Conceptual Frameworks of 1989, 2010, and 2018 were investigated. To compare them, a cross-sectional survey including literature and document review was conducted. In particular, the real documents issued in July 1989, September 2010, and March 2018 were investigated to verify the prior publications and achieve the aim of the study. The Conceptual Frameworks of 1989, 2010, and 2018 helped to construct a comparative table and highlight the major changes in the revised Conceptual Framework in 2018. Overall, it helped to get an answer to RQ1.

In the second step, the obtained major changes were grouped into four categories. As mentioned above, the categories were constructed according to the following context of changes: a) filling gaps that were mentioned in the prior literature as the lack of the Conceptual Framework-2010 were signed as into the "Filling gaps" 
Shkulipa, L., (2021)

Grouping of major changes in conceptual framework of financial reporting and analysis of new challenges

group, b) clarification of uncertainties of past concepts (1989) and return them without or with any changes to the new version of the Conceptual Framework, which are assumed to be the main advantage of the Conceptual Framework IASB 2018 - in the "Clarifying" group, c) corrected priority concepts of the purpose of financial reporting, the enhancing qualitative characteristics - in the "Priority" group, d) updates that did not exist in none of the Conceptual Framework versions previously - in the "Updating" group. Overall, it helped to get an answer on RQ2 and find out whether the major changes in the Conceptual Framework are new difficulties between the understanding of practitioners and standard-setters (RQ3). In the third step, considering similar studies (Swapan, 2012; Cade et al., 2019) about the challenges in the Conceptual Framework, it was concluded that the revised structure of the Conceptual Framework is more comprehensive than previous ones. The new version of the Conceptual Framework covers all aspects of setting standards from general purpose financial reporting to the presentation and disclosure target. The used methods are considered also important contributions to the research methodology of the study that may be related to the Conceptual Framework comparison, view, analysis in further consideration or investigation.

\section{Research results}

The revised structure of the Conceptual Framework is more comprehensive than the previous ones (see Appendix A). This provides the IASB with more up-to-date standards-setting tools. The new version of the Conceptual Framework covers all aspects of setting standards from general purpose financial reporting to the presentation and disclosure purposes. Some chapters of the Conceptual Framework are only aimed for IASB, such as the use of other comprehensive income (OCI). According to the leader of KPMG, R. Dotslav:'This substantially confirms the existing trajectory of development of accounting standards of IASB" (KPMG, 2018).

The first group was identified as a "Priority" by stakeholders in the 2011 Agenda Consultation. For example, the concept of useful financial information (relevant and faithfully represented) is consistently distributed through all chapters of the revised Conceptual Framework (what was not existing in the old versions) and is expected to make ultimately financial information more useful to various stakeholders. In addition to it, the Conceptual Framework establishes the cost constraint on useful financial reporting: "reporting financial information imposes costs, and those costs must be justified by the benefits of reporting that information" (p. 2.39 of CF, 2018, see p. 2.39). It should be noted that two other constraints (timeliness, the balance between qualitative characteristics) issued by the Conceptual Framework of 1989 were excluded from the new context of the Conceptual Framework. Timeliness, currently, is the enhancing qualitative

32 S sciendo Studia Universitatis "Vasile Goldis" Arad. Economics Series Vol 31 Issue 2/2021 ISSN: 1584-2339; (online) ISSN: 2285 - 3065

Web: publicatii.uvvg.ro/index.php/studiaeconomia. Pages $20-44$ 
Shkulipa, L., (2021)

Grouping of major changes in conceptual framework of financial reporting and analysis of new challenges

characteristic of financial reports, but also may be considered as a constraint. If there is an unjustified delay in the presentation of information, it may lose its relevance, but on the other hand, a faithful representation takes time to clarify all the transactions.

The second group of changes - "Filling gaps" - highlights guidance on factors for selecting the measurement basis, assets and liabilities recognition, presentation, and disclosure of the financial information in the Income statement. Taking into account the reference in the standards to a reporting entity, this explanation as "an entity voluntarily (or required) decides to present general-purpose financial statements" into the Conceptual Framework has been added.

Some of the concepts in the revised document are completely new. Therefore, the third group of changes, "Updating" (see Appendix A) presents: (a) "no ability to avoid' approach for the current obligation; (b) 'set of rights' approach for assets, (c) 'derecognition', (d) disclosure of information guidance, (e) new categories of measurement methods, (f) 'measurement uncertainty, (g) consolidated, unconsolidated and combined statements, (h) 'executory contracts', (i) 'unit of account'.

(a) The old rules for liability recognition are not already existing. The challenge will be defining which future transactions of the entity have 'no practical ability to avoid'. In some cases which are considered in p. 5.14 (CF, 2018), it might be uncertain whether the act occurred until a court decision. For better understanding, the Board explains the following circumstances for this occurrence (CF, 2018, p. 4.32-4.34):

- "liability caused by practice" - if duty or responsibility arises from the entity's customary practices, published policies or specific statements - the entity has an obligation if it has no practical ability to act in a manner inconsistent with those practices, policies or statements;

- if duty or responsibility is conditional on a particular future action that the entity itself may take - the entity has an obligation if it has no practical ability to avoid taking that action;

- the entity can avoid a transfer only by liquidating the entity or by ceasing to trade;

- if any action favorable to the avoidance of the transfer of the resource has more disadvantageous economic consequences than the transfer itself (CF, 2018). At the same time, the IASB is weakening this concept, making it depends on the factors that measure the practical ability to avoid the transfer of an economic resource, the nature of the entity's duties, or responsibilities. Given above (c), the intention to make a transfer or high probability of this transfer is not sufficient reason to believe that there is no practical ability to avoid the transfer. And this innovation requires the use of additional valuation judgments in practice. 
Shkulipa, L., (2021)

Grouping of major changes in conceptual framework of financial reporting and analysis of new challenges

(b) From an accounting perspective, a physical object is not directly an asset because conceptually, an asset is an economic resource, while the economic resource is the set of rights. For example, in some circumstances, a company would recognize as an asset a right to use an aircraft, rather than an aircraft itself. In principle, the rights of each entity are separate assets. The challenge will be defining to what extent an asset can be split into different rights (the right to use the object; the right to sell rights over the object; the right to pledge rights over the object; and many other rights) and the impact on recognition and derecognition).

Current significant changes in the assets and liabilities definitions make it clear that an asset is an existing economic resource, not the ultimate inflow of economic benefits, and the liability is an obligation to transfer an economic resource, not the ultimate outflow of economic benefits. These changes are significantly based not on describing both in terms of an expected flow of benefits. The latter had previously been interpreted as a probability threshold. Therefore, currently, both the determinations of an asset and a liability do not need to be certain or probable that economic benefits will arise - their flow expectations are deleted from the new concepts.

The practice evidenced that old definitions of assets and liabilities have worked well in the past. Therefore, these changes have not been made to appropriate Standards that use the 'old' definition of liability such as IAS 37 'Provisions, Contingent Liabilities and Contingent Assets' or IFRIC 21 'Levies'. Currently, the users of IFRS 3 and IAS 8 should apply the definitions of an asset and a liability (and additional concepts) according to the Conceptual Framework 2010. For example, IFRS 3's users need to decide whether to recognize assets and liabilities as part of a business combination. The IASB acknowledged that in some cases, the application of revised definitions really might change which assets and liabilities can be recognized in a business combination. Eventually, post-acquisition accounting may lead to the immediate derecognition of these assets or liabilities, resulting in "nominal incomes or losses" that do not reflect economic incomes or losses (Thornton, 2018), including avoidance of double-revisions to accounting policies by entities. Therefore, the IASB is looking for ways to update IFRS 3 without unintended consequences, while the companies have a transitional period. Although the Conceptual Framework, IFRSs, IASs, and IFRIC 21 are now a little inconsistent, the requirements in a Standard or Interpretations will always prevail.

(c) The new control-based approach of derecognition is explained that an entity will take an asset off-balance-sheet when it loses control over all or part of this asset, the focus is no longer on the transfer of risks and benefits. The challenge will be defining what to do if the entity retains some rights after the transfer.

(d) The current disclosure guidance provides a detailed classification of assets, liabilities, equity, income, and expenses with a description of offsetting,

34 S sciendo Studia Universitatis "Vasile Goldis" Arad. Economics Series Vol 31 Issue 2/2021 ISSN: 1584-2339; (online) ISSN: 2285 - 3065

Web: publicatii.uvvg.ro/index.php/studiaeconomia. Pages $20-44$ 
Shkulipa, L., (2021)

Grouping of major changes in conceptual framework of financial reporting and analysis of new challenges

aggregation, profit and loss distinction, and other comprehensive income. However, in practice, it was found the absence of specific guidance of including specific items in other comprehensive income or the income statement difficult. Therefore, setting new standards, in the future the IASB expects to include an impossibility of reclassification of income and expenses included in other comprehensive income.

(e) New measurement basis - based on historical cost and current value - have expanded explanations, take into account cash flow-based measurement techniques, explain the use of more than one measurement basis and reflect their changes in the income statement or other comprehensive income, and introduce the new concept of "central estimated measurement" for the uncertainty of future cash flows in terms of statistics.

(f) The new concept of "measurement uncertainty" as an aspect of the faithful presentation of useful financial information in link with the free of error information has been singled out. It is stated that the need to use central estimates to reduce probable errors or omissions in the information creates measurement uncertainty, which, in turn, does not prevent the information to be useful. However, this does not necessarily mean that a high level of measurement uncertainty prevents items from providing useful information. Therefore, it is assumed that the information with less measurement uncertainty is more useful.

(g) Consolidated, unconsolidated, or combined financial statements are presented as separate forms of financial statements. The complication of this change is that the Conceptual Framework does not indicate when or how entities may prepare combined financial statements (p. 3.12 consist only definition of combined financial statement).

(h) A new concept of "executory contract" has explained a contract or part of it that is considered as unenforceable by both parties - with detailed instructions for its application.

(i) A new concept of "unit of account" as a right or obligation, or a group of rights and responsibilities, that apply the recognition criteria and measure to, has been added. It is stated that the decision on the choice of unit of account is guided by the standards, but the factors that should be taken into account in recognition of it - by the Conceptual Framework.

And the last group of changes (see Appendix A) - "Clarifying" - contains the role of "substance over form", "stewardship", "prudence". It might influence the faithful representation of an item. A reply to much feedbacks, the IASB has reintroduced prudence as a fundamental qualitative characteristic that was deleted from the 2010 Conceptual Framework. The revised notion of prudence purports the exercise of caution when making judgments under uncertain conditions. At the same time, it clarifies that prudence does not imply a need for asymmetry (see 
Shkulipa, L., (2021)

Grouping of major changes in conceptual framework of financial reporting and analysis of new challenges

Figure 2). The revised Conceptual Framework clarifies that recognition is only relevant if it leads to both relevant information about the recognized element of the financial statement and a faithful representation of that element. Besides, the Conceptual Framework currently emphasizes the importance of providing the information needed to assess management's stewardship. It states explicitly that a faithful representation of a transaction or event reports its substance rather than merely its legal form.

As a result, the implications of results are two-fold. First, the results indicate that the revised structure of the Conceptual Framework is more comprehensive than the 1989th and 2010th Conceptual Frameworks. It is confirmed by the observed 320 paragraphs, 8 chapters of the revised Conceptual Framework for Financial reporting. As a result, useful and required improvements of the Conceptual Framework, although incomplete, help to make a comprehensive set of concepts for financial statements. Some areas such as the distinction between liabilities and equity have been removed from the new Conceptual Framework with the plan to refer it in separate projects. It is noted that the context, the structures, and the accounting concepts of all frameworks $(1989,2010$, and 2018) differ significantly (answer on RQ1).

Second, this paper shows the effectiveness of new changes in the Conceptual Framework to the understanding between practitioners and standard-setters (answer on RQ3). Understanding the probability threshold before and after changes in asset and liability definitions showed that old asset and liability definitions did not affect judgments about their availability, and participants used a higher probability threshold in recognizing assets than in recognizing liabilities (before changes). After the probability threshold of assets and liabilities recognition was abolished, conducted experiments have shown that more people define assets and liabilities more symmetrically. It gives a more significant consistency (but not ideally) with the IASB's intent. In this way, the effects of new changes in asset and liability definitions improve the realization of the IASB goals and better align participants' judgments with the setters' intentions.

As a result, an asset (not as a physical object) as a set of rights in interpreting a current economic resource that is controlled by an entity as a result of past events, and an obligation (not as a final outflow of economic benefits) as an entity's current obligation to transfer an economic resource as a result of past events have been reinterpreted for the following reasons: 1) different interpretations of probability and expected benefits between practitioners and standard-setters; 2) frequent use an asymmetric identification of an asset and liability. The found different formulations of these interpretations encourage a rethinking of past practices by the standardsetters and moving towards the symmetry of assets and liabilities identification.

36 Sciendo Studia Universitatis "Vasile Goldis" Arad. Economics Series Vol 31 Issue 2/2021 ISSN: 1584-2339; (online) ISSN: 2285 - 3065

Web: publicatii.uvvg.ro/index.php/studiaeconomia. Pages $20-44$ 
Shkulipa, L., (2021)

Grouping of major changes in conceptual framework of financial reporting and analysis of new challenges

Third, the findings summarize that Huber's critique (Huber, 2020) of the FASB Conceptual Framework does not match the revised IASB Conceptual Framework, because the last version of IASB's document has received new definitions of resources that eliminate their misuse. Also, internal inconsistencies were largely avoided by changes grouped in the "Clarifying" category (answer on RQ2). The contradictory statements in the IASB Conceptual Framework are reduced comparing to the FASB's concepts or previous IASB's concepts. Although their probable inconsistency with the existing IFRS is already existing. Indeed, the old definitions of financial reporting elements of the Conceptual Frameworks 1989th or $2010^{\text {th }}$ versions are used in IAS 16, IAS 23, IAS 38, IAS 36, IAS 37, IFRS 3, IFRS 15, IFRS 16 currently. It was confirmed that some IFRS are not justified within only the Conceptual Framework (Kabir et al., 2018). However, their further improvements are planned to be added by the standard-setters, which might be the subject for further research.

Besides, the findings showed that the revised Conceptual Framework consists of new gaps, particular, the challenge might be defined: 1) which future transactions of the entity have 'no practical ability to avoid'; 2) what extent an asset can be split into different rights (the right to use the object; the right to sell rights over the object; the right to pledge rights over the object; and many other rights); 3 ) what to do if the entity retains some rights after the transfer; 4) when income included in the other comprehensive income should be reclassified; 5) were to include particular items in other comprehensive income statement or the income statement; 6) when and how entities may prepare combined financial statements; 7) when the old definitions of assets and liabilities are required by IFRSs or IASs (answer on RQ4). Most of the current challenges in the Conceptual Framework for Financial Reporting were found in the "Updating" group (answer on RQ2).

As a result, it was argued the new phrase in the current obligation definition - "no ability to avoid" - as the disadvantage of the changes that complicate the feasibility of innovations because it requires the use of additional valuation judgments in practice. Thus, the results of this paper controverted the external validity of the prior studies on reducing the judgments (Dhanda et al., 2018). Indeed, some judgments need to be used in practices when recognizing fair value, the probability of credit and other risks to future cash flows, materiality threshold, business model, probability of event occurrence before the revenue recognition, assets, and liabilities symmetric recognition, capitalization of biological assets. As judgment is one step toward revenue manipulation and intentional fraud, the updated Conceptual Framework does not completely close all of these judgments even after the changes. Although it is noted that the update has improved its reliability status in a fuller coverage of financial reporting concepts. From a practical point of view, all these judgments remain the prerogative of the business entity, from a theoretical 
Shkulipa, L., (2021)

Grouping of major changes in conceptual framework of financial reporting and analysis of new challenges

point of view - researchers, academics, developers. Therefore, this study is the basis for further research in terms of each of these complications in the new Conceptual Framework for IFRS.

\section{Conclusions}

The purpose of this paper was to find out the new gaps in the current Conceptual Framework (RQ4), research the major changes in the Conceptual Framework of Financial Reporting-2018 (RQ1), and group them into the "Priority", "Filling gaps", "Updating" and "Clarifying" categories (RQ2), analyze the current difficulties of these changes in a consistent understanding by standard-setters and practitioners (RQ3). As a result, the implications of results are two-fold. First, the results indicate that the revised structure of the Conceptual Framework is more comprehensive than the 1989th and 2010th Conceptual Frameworks. Second, this paper shows the effectiveness of new changes in the Conceptual Framework to the understanding between practitioners and standard-setters. Third, the findings summarize that Huber's critique (Huber, 2020) of the FASB Conceptual Framework does not match the revised IASB Conceptual Framework, because the last version of IASB's document has received new definitions of resources that eliminate their misuse.

Besides, the findings showed that the revised Conceptual Framework consists of new gaps, particular, the challenge might be defined with 'no practical ability to avoid'; while splitting assets into different rights; if the entity retains some rights after the transfer; while reclassifying income and other comprehensive income; while preparing combined financial statements; using the old definitions of assets and liabilities required by IFRSs or IASs. Most of the current challenges in the Conceptual Framework for Financial Reporting were found in the "Updating" group.

In the conclusion, it was obtained the Conceptual Framework primarily is a tool for the IASB to develop standards and to assist the IFRS Interpretations Committee in interpreting them. IFRSs and any inconsistencies with the revised Conceptual Framework will need to take some time to specify. The current gaps of the Conceptual Framework are already testing in practice by preparers of financial statements and the IASB standard-setters. Although some companies are expecting to have these inconsistencies not often because they already use the Conceptual Framework-2010 as a guide while selecting their accounting policies if there are no specific IFRS requirements. However, they will need to apply the new Conceptual Framework' guidance retrospectively as of 1 January 2020 taking into account the new requirements in IFRSs. Thus, the results of the study suggest that the Conceptual Framework is a logical and holistic system with its autocratic

38 S sciendo Studia Universitatis "Vasile Goldis" Arad. Economics Series Vol 31 Issue 2/2021 ISSN: 1584-2339; (online) ISSN: 2285 - 3065

Web: publicatii.uvvg.ro/index.php/studiaeconomia. Pages $20-44$ 
Shkulipa, L., (2021)

Grouping of major changes in conceptual framework of financial reporting and analysis of new challenges

declarations and a somewhat significant number of assumptions that need to be checked by practice and time.

\section{Acknowledgments}

The author thanks the very useful remarks of the two anonymous reviewers and editor of the journal Studia Universitatis „Vasile Goldiș” Arad - Economics Series.

\section{Funding}

This research received no specific grant from any funding agency in the public, commercial, or not-for-profit sectors.

\section{Author Contributions}

The entire article was written by Shkulipa Liudmyla. The author conceived the study, carried out the literature review section, and was responsible for the design, data collection, data analysis, and interpretation.

\section{Disclosure Statement}

The authors have not any competing financial, professional, or personal interests from other parties.

\section{References}

1. Abdel-Khalik, A.R., (2019), Failing Faithful Representations of Financial Statements: Issues in Reporting Financial Instruments. Abacus, 55: 676-708, doi:10.1111/abac.12176

2. Barker, R., Penman, S.H., (2018), Moving the Conceptual Framework Forward: Accounting for Uncertainty. Contemporary Accounting Research, Forthcoming, Columbia Business School Research Paper No. 18-54

https://doi.org/10.1111/1911-3846.12585

3. Barker, R., Penman, S., (2013), Moving the Conceptual Framework Forward: Accounting for Uncertainty, „Journal China Journal of Accounting Studies”, 37, 322-357, doi:10.1111/1911-3846.12585

4. Barth, M.E., (2014), Measurement in Financial Reporting: The Need for Concepts, Accounting Horizons 28 (2014), pp. 331-352

https://doi.org/10.2308/acch-50689

5. Barth, M.E., Clinch, G., Shibano, T., (2003), Market Effects of Recognition and Disclosure, Journal of Accounting Research 41 (2003), pp. 581-609

6. Basu, S. (1997), The Conservatism Principle, and the Asymmetric Timeliness of Earnings, Journal of Accounting and Economics 24 (1997), pp. 3-37 
Shkulipa, L., (2021)

Grouping of major changes in conceptual framework of financial reporting and analysis of new challenges

7. Beerbaum, D., Piechocki, M., (2016), IFRS 9 for Financial Institutions - The Case for IFRS and FINREP Taxonomies - A Conceptual Gap Analysis. http://dx.doi.org/10.2139/ssrn.2857939

8. Bernstein, P.L., (1998), Against the gods: The remarkable story of risk, New York, NY: Wiley

9. Bromwich, M., Macve, R.H., Sunder, S., (2010), Hicksian Income in the Conceptual Framework, Abacus 46, pp. 348-376. https://doi.org/10.1111/j.14676281.2010.00322.x

10. Bullen, H.G., Crook, K., (2005), Revisiting the Concepts: A New Conceptual Framework Project, Retrieved from http://www.fasb.org (accessed 31/03/2020)

11. Bunting, M.B., (2010), The Unit of Account in Financial Reporting: A Set of Conceptual Framework Problems. http://dx.doi.org/10.2139/ssrn.2740236

12. Cade, N.L., Koonce, L., Mendoza, K.I., Rees, L., Tokar, M.B., (2019), Assets and Liabilities: When Do They Exist?, „Contemporary Accounting Research”, 36, s. 553-587. doi: 10.1111/1911-3846.12479

13. Conceptual Framework for Financial Reporting (2018), Croner-i: HR-TaxH\&S-Audit\&Accounting, retrieved from:

https://library.croneri.co.uk/cch_uk/iast/miscconceptualfram2018-201803

14. Cordery, C.J., Sinclair, Rowena M.S., (2016), Decision-Usefulness and Stewardship As Conceptual Framework Objectives: Continuing Challenges. https://doi.org/10.2139/ssrn.2918784

15. Davern, M., Gyles, N., Hanlon, D., Pinnuck, M., (2019), Is Financial Reporting Still Useful? Australian Evidence. Abacus, 55: 237-272. doi:10.1111/abac.12152

16. Dhanda, M., Mangala, D., (2018), Earnings Management: Conceptual Framework and Research Developments (2018). The IUP Journal of Accounting Research \& Audit Practices, Vol. XVII, No. 4, pp. 7-20, Available at SSRN: https://ssrn.com/abstract=3373507

17. Gordon, E.A., Bischof, J., Daske, H., Munter, P., Saka, C., Smith, K.J., Venter, E.R., (2015), The IASB's Discussion Paper on the Conceptual Framework for Financial Reporting: A Commentary and Research Review. Journal of International Financial Management \& Accounting, Vol. 26, Issue 1, pp. 72-110, http://dx.doi.org/10.1111/jifm.12024

18. Handley, K., Evans, E., Wright, S., (2020), Understanding participation in accounting standard-setting: the case of AASB ED 192 Revised Differential Reporting Framework. Account Finance. doi:10.1111/acfi.12490

19. Healy, P.M., Palepu, K.G., (2001), Information Asymmetry, Corporate Disclosure, and the Capital Markets: A Review of the Empirical Disclosure Literature, Journal of Accounting and Economics 31, pp. 405-440. https://doi.org/10.1016/s0165-4101(01)00018-0 https://doi.org/10.1111/1475-679x.00117

40 Sciendo Studia Universitatis "Vasile Goldis" Arad. Economics Series Vol 31 Issue 2/2021 ISSN: 1584-2339; (online) ISSN: 2285 - 3065

Web: publicatii.uvvg.ro/index.php/studiaeconomia. Pages $20-44$ 
Shkulipa, L., (2021)

Grouping of major changes in conceptual framework of financial reporting and analysis of new challenges

20. Huber, W.D., (2020), The FASB Conceptual Framework - A Case of the Emperor's New Clothes. Journal of Accounting, Ethics and Public Policy 21(1): 77-114, https://doi.org/10.2139/ssrn.3400769

21. Johnson, L., (2004), The Project to Revisit the Conceptual Framework, The FASB Report, December 28: 4-7

22. Kabir, H., Rahman, A., (2018), How Does the IASB Use the Conceptual Framework in Developing IFRSs? An Examination of the Development of IFRS 16 Leases. Journal of Financial Reporting In-Press. https://doi.org/10.2308/jfir-52232 23. Kahneman, D., Frederick, S., (2002), Representativeness revisited: Attribute substitution in intuitive judgment, In T. Gilovich, D. Griffin, and D. Kahneman (eds.), Heuristics and Biases: The Psychology of Intuitive Judgment, Cambridge University Press, Cambridge, UK, pp. 49-81

24. Kesjan, S.V., Mullinova, S.A., (2017), The Conceptual Framework as a builder of the IFRS, „Science online journal «Konthept», s. 459-462. Retrieved from http://e-koncept.ru/2017/570091.htm [Russian] (accessed 06/08/2019)

25. KPMG, (2018), Conceptual Framework - The new foundation for IFRS, Retrieved from https://home.kpmg/xx/en/home/insights/2018/03/revisedconceptual-framework-290318.html (accessed 08/10/2019)

26. Pounder, B., (2010), A common framework for accounting standards, Strategic Finance, November, Retrieved from http://findarticles.com/p/articles/mi_hb6421/ is_5_92/ai_n56550179/(accessed 08/06/2019)

27. Rodgers, P., (2007), International Accounting Standards: From UK standards to IAS - an accelerated route to understanding the key principles, Jordan Hill, Oxford, UK: CIMA Publishing is an imprint of Elsevier.

28. Saunders, M., Lewis, P., Thornhill, A., (2012), Research Methods for Business Students. 6th edition, Pearson Education Limited.

29. Smieliauskas, W., (2015), Auditability of Accounting Estimates and the IASB's Conceptual Framework Exposure Draft. http://dx.doi.org/10.2139/ssrn.2715741

30. Smieliauskas, W., Craig, R., Amernic, J., (2017), GAAP as Ineffective Legal Defense of Financial Reporting: Implications for Truthfulness, Auditability, and the IASB's Proposed 2015 Conceptual Framework. Canadian Academic Accounting Association (CAAA) Annual Conference,

http://dx.doi.org/10.2139/ssrn.2899074

31. Sutton, D.B., Cordery, C.J., van Zijl, T., (2015), The Purpose of Financial Reporting: The Case for Coherence in the Conceptual Framework and Standards. Abacus, Vol. 51, Issue 1, pp. 116-141, 2015, http://dx.doi.org/10.1111/abac.12042 32. Swapan, K., (2012), The Conceptual Framework for Financial Reporting 2010: Some Reflective Comments. Independent Business Review, Vol. 5, No. 2. Available at SSRN: https://ssrn.com/abstract=3037304 
Shkulipa, L., (2021)

Grouping of major changes in conceptual framework of financial reporting and analysis of new challenges

33. Thornton, D.B., (2015), Different Conceptual Accounting Frameworks for Public and Private Enterprises: Commentary on Canada's IFRS Transition and Suggestions for International Empirical Work. Account Perspect, 14: 168-189. doi:10.1111/1911-3838.12048

34. Thornton, G., (2018), As instinct for growth. IFRS News, Special Edition, A revised Conceptual Framework Financial Reporting.

Appendix A

Comparative table of major changes in the Conceptual Framework for Financial Reporting in 2018 to 1989 and 2010 versions

\begin{tabular}{|c|c|c|c|c|}
\hline \multirow{2}{*}{$\begin{array}{l}\text { Document } \\
\text { Structure }\end{array}$} & \multicolumn{3}{|c|}{ Issued Date of the Conceptual Framework for Financial Reporting } & \multirow{2}{*}{$\begin{array}{l}\text { Group of } \\
\text { Changes }\end{array}$} \\
\hline & July 1989 & September 2010 & March 2018 & \\
\hline Preface & $1-4$ & - & - & - \\
\hline Purpose & 5 & $\mathrm{~V}$ & - & - \\
\hline Status and purpose & - & - & SP1.1-SP1.5 & - \\
\hline Scope & $6-8$ & $\mathrm{~V}$ & - & - \\
\hline \multirow[t]{2}{*}{$\begin{array}{l}\text { The objectives of } \\
\text { financial } \\
\text { statements }\end{array}$} & $12-21$ & \multirow{2}{*}{$\begin{array}{l}\text { Chapter } 1 \\
\text { «The objective of the } \\
\text { general-purpose } \\
\text { financial reporting» } \\
\text { OB1-OB21 }\end{array}$} & $\begin{array}{c}\text { Chapter } 1 \\
\text { «The objective of the } \\
\text { general-purpose financial } \\
\text { reporting» } \\
1.1-1.23\end{array}$ & - \\
\hline & $\begin{array}{l}\text { The concept of } \\
\text { management activities in } \\
\text { the interests of owners }\end{array}$ & & Added back «stewardship» & Clarifying \\
\hline $\begin{array}{l}\text { Users and their } \\
\text { information needs }\end{array}$ & $\begin{array}{l}\text { a wide range of users and } \\
\text { they include "present and } \\
\text { potential investors, } \\
\text { employees, lenders, } \\
\text { suppliers, and other trade } \\
\text { creditors, customers, } \\
\text { governments and their } \\
\text { agencies and the public" } \\
\text { (p. 9) }\end{array}$ & $\begin{array}{l}\text { existing and potential } \\
\text { investors, lenders and } \\
\text { other creditors are } \\
\text { "primary users" [para } \\
\text { OB2] and customers, } \\
\text { government and their } \\
\text { agencies who may be } \\
\text { interested in financial } \\
\text { reports but are not } \\
\text { primary users [para } \\
\text { BC1.10] }\end{array}$ & $\begin{array}{l}\text { primary users (of general- } \\
\text { purpose financial reports) } \\
\text { are the entity's existing and } \\
\text { potential investors, lenders, } \\
\text { and other creditors } \\
\text { (para } 1.2 \text { ) } \\
+ \text { management (1.9) } \\
+ \text { regulators and members of } \\
\text { the public }(1.10)\end{array}$ & Filling gaps \\
\hline $\begin{array}{l}\text { Underlying } \\
\text { assumption }\end{array}$ & $22-23$ & 4.1 & 3.9 & - \\
\hline $\begin{array}{l}\text { Qualitative } \\
\text { characteristics of } \\
\text { financial } \\
\text { statements }\end{array}$ & $24-46$ & $\begin{array}{l}\text { Chapter 3 "Qualitative } \\
\text { characteristics of } \\
\text { useful financial } \\
\text { information" } \\
\text { QC1-QC39 }\end{array}$ & $\begin{array}{c}\text { Chapter } 2 \text { "Qualitative } \\
\text { characteristics of useful } \\
\text { financial information" } \\
2.1-2.43\end{array}$ & - \\
\hline \multirow{6}{*}{$\begin{array}{l}\text { - Fundamental } \\
\text { qualitative } \\
\text { characteristics }\end{array}$} & - & $\mathrm{v}$ & V & - \\
\hline & Relevance & Relevance & Relevance & Priority \\
\hline & - Predictive role & - Predictive role & - $\quad$ Predictive role & - \\
\hline & - Confirmatory role & - Confirmatory role & - Confirmatory role & - \\
\hline & - Materiality & - Materiality & - $\quad$ Materiality & - \\
\hline & Reliability & - & - & - \\
\hline
\end{tabular}


Shkulipa, L., (2021)

Grouping of major changes in conceptual framework of financial reporting and analysis of new challenges

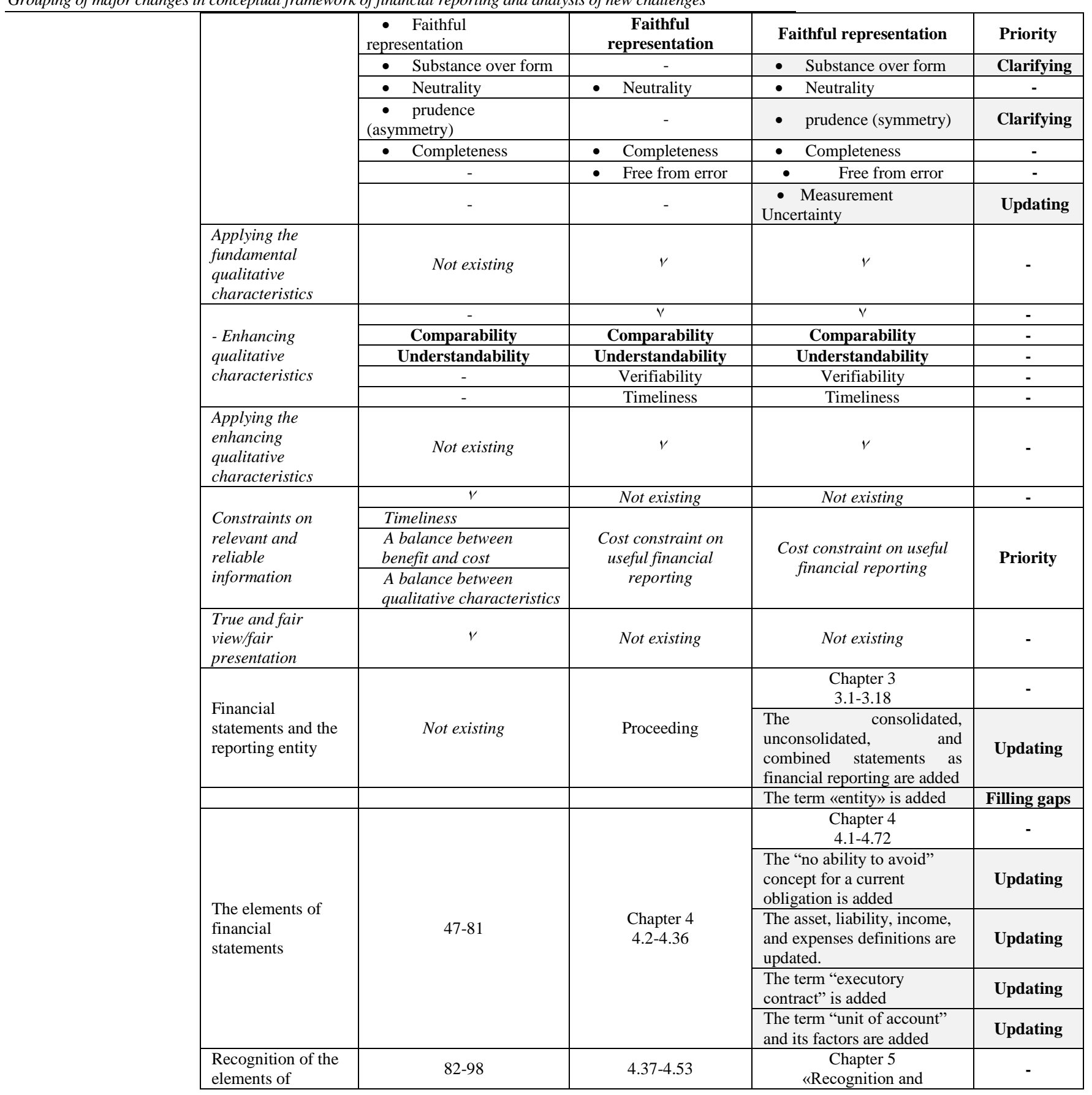


Shkulipa, L., (2021)

Grouping of major changes in conceptual framework of financial reporting and analysis of new challenges

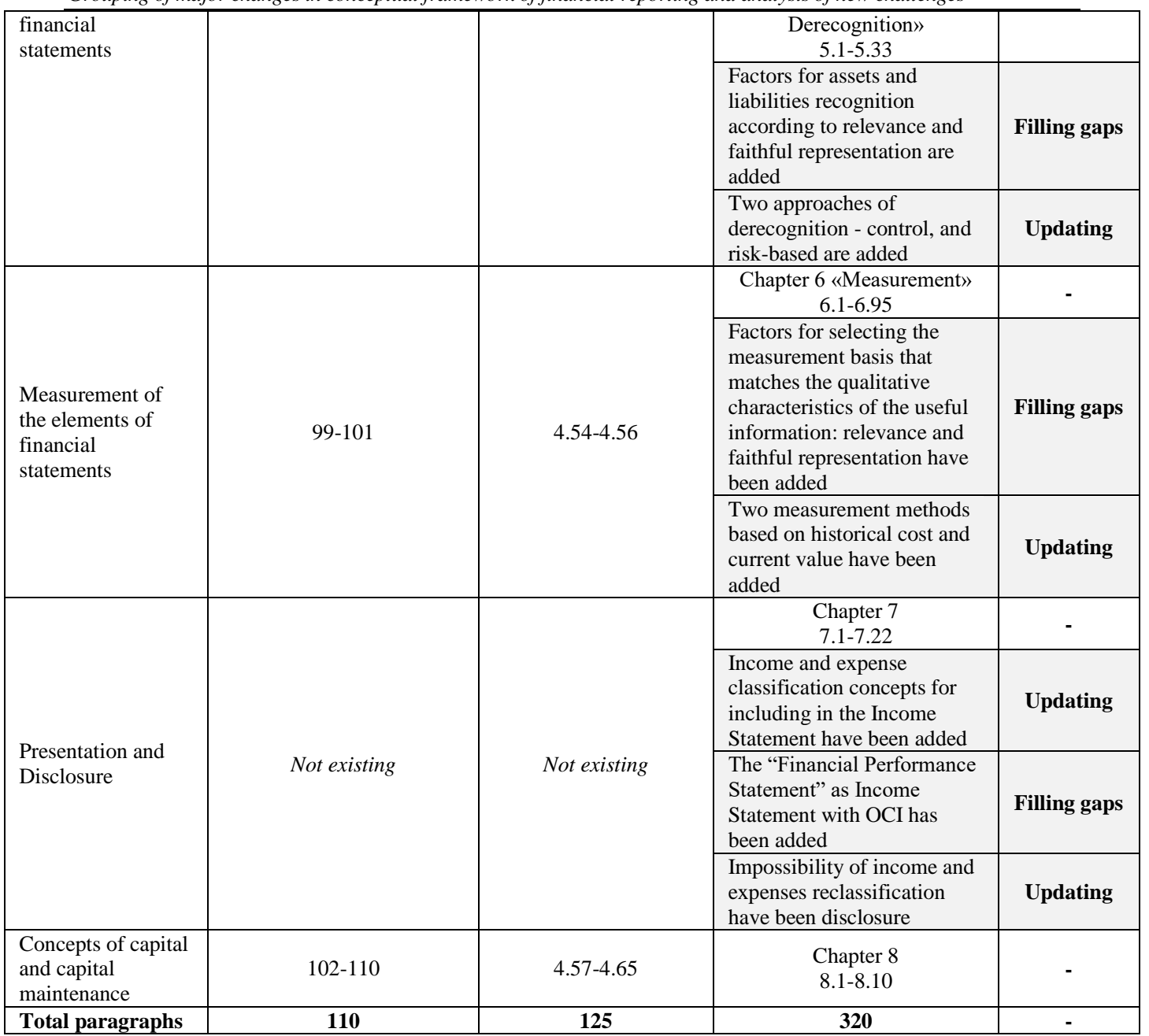

Note. The new changes in the Conceptual Framework are grey-highlighted.

Source: developed by the author 